\title{
Study of Rotor Asymmetry Effects of an Induction Machine by Finite Element Method
}

\section{Lebaroud Abdesselam ${ }^{\dagger}$ and Clerc Guy*}

\begin{abstract}
This paper presents a study on rotor asymmetry caused by broken bars and its effects on the stator current of an induction machine under an unbalanced supply voltage. The simulation of the induction machine is based on the finite element method. In the early stage of diagnosis, we show new sidebands specific to the partial rupture of the rotor bar. Experimental tests corroborate with the simulation results.
\end{abstract}

Keywords: Broken bars, Induction machine, Finite element method

\section{Introduction}

In recent years, intensive research efforts have been focused on the motor current signature analysis to monitor and diagnose the fault condition of induction machines [1][5]. This fault produces a relatively significant localized disturbance of the magnetic flux in the air-gap, whereas faults, such as rotor eccentricity, produce a more propagated disturbance, hence generating weaker harmonic rotating fields [6]. Several equations have been presented to generalize the consequences of broken bars on the stator current. Deleroi [7] explained that the additional air gap field, produced by the rotor asymmetry, induces voltage within the stator windings, which contain a fundamental frequency along with many other high frequency components.

The main effect of the broken bars is the amplitude modulation of the stator current. It is characterized by the upper and lower sidebands. The formula used to calculate the components has been proven by Hargis [8]:

$$
f_{s}(1 \pm 2 k s)
$$

$K=1,2, \ldots$

$f_{s}:$ frequency

Filippetti [9] explained how the interaction of the $(1-2 k s) f_{s}$ harmonic of the motor current with the fundamental air-gap flux produces speed ripple at $2 s f_{s}$ and gives rise to additional motor current harmonics at frequencies $(1+2 k s) f_{s}$.

Perovic [10] showed that when faults of both broken bars and stator turns short circuits appear at the same time, the sideband components $(1 \pm 2 k s) f_{s}$ and $-(1 \pm 2 k s) f_{s}$

$\dagger$ Corresponding author: Université 20 Août 1955, Skikda, et le laboratoire LEC. (lebaroud@yahoo.fr)

* Université de Lyon, Lyon, F-69622, France; université Lyon 1, Lyon, F-69622, France; CNRS, UMR5005, Laboratoire AMPERE, Villeurbanne, F-69622, France.

Received: April 13, 2010; Accepted: December 1, 2010 appear respectively around the fundamental $\left(f_{s}\right)$ and the negative sequence current $\left(-f_{s}\right)$. Subhasis [11] demonstrated that broken bar sidebands also appear around the $5^{\text {th }}$ and $7^{\text {th }}$ time harmonics. Research on rotor dissymmetry is focused only on the formula (1), which describes only the visible part of the fault. To show all the broken rotor bar frequencies in the motor current for both healthy and fault machines, a more precise model is required. The analytical models dedicated to the diagnosis and are developed in the literature [12]-[14] are often penalized by simplified assumptions, particularly in the distribution of the magnetic flux density in the air-gap. The important information is likely to be omitted partially or completely if one considers only the fundamental of the magnetic flux density. However, a more precise model of the machine is necessary for an accurate analysis of the machine behavior in both healthy and faulty cases. A detailed analysis of the broken rotor bar requires a precise model. These analytical models represent the electrical behavior of the equivalent induction machine. They also do not take into account the electric or magnetic phenomena, such as induced currents, magnetic saturation, and effects of complex geometry. Therefore, these assumptions lead to the omission of relevant information on the machine condition. For a more precise modeling of the induction machine, considering its electromagnetic behavior is necessary. The numerical resolution of Maxwell's equations governing the machine operation and the reduction of simplifications introduced in the previous models lead to a model that is closer to the real machine. The two-dimensional modeling of the induction machine greatly reduces the computation time and memory space used. The magnetic losses due to coil heads are considered. In this paper, we use a model based on a magnetodynamic and transient magnetic formulation of the induction motor using the FLUX2D software. The simulation and experimental verification allow an accurate analysis of the effects of broken bars with the consideration of the non-ideal stator currents. 


\section{Finite element model of induction motor}

The study of the behavior of electromagnetic systems depends on their operating modes. Several formulations are possible, such as electrostatics, electrodynamics, magnetostatics, magnetodynamic, etc. The induction motor has a dynamic that we cannot neglect in the study; thus, we study the magneto-evolving. This allows us to follow the temporal and transient behavior of the machine.

The software used in this study is FLUX2D @ Cedrat [15]. It achieves the magnetic circuit scheme in two dimensions. Our choice is oriented towards the plane perpendicular to the rotation axis of the machine and that develops the electromagnetic field.

Magnetic leaks in the coil heads are considered in the developed model. They are presented by the calculations of leakage inductance. The FLUX2D software allows the realization of the magnetic circuit scheme in two dimensions. The coupling of our magnetic scheme with an electrical circuit allows us to follow the dynamic behavior of the machine. The FLUX2D software solves the following equation:

$$
\sigma_{e} \frac{d \vec{A}}{d t}+\operatorname{rot}\left(\frac{1}{\mu \operatorname{rot}(\vec{A})}\right)=J+\operatorname{rot}(\vec{H})
$$

cording to polar periodicity. The rotating air gap is represented (Fig. 1). Modeling half or a quarter of the machine considering its symmetry is possible. However, with the introduction of fault, this consideration is not valid all the time. Therefore, we used the full representation of the machine.

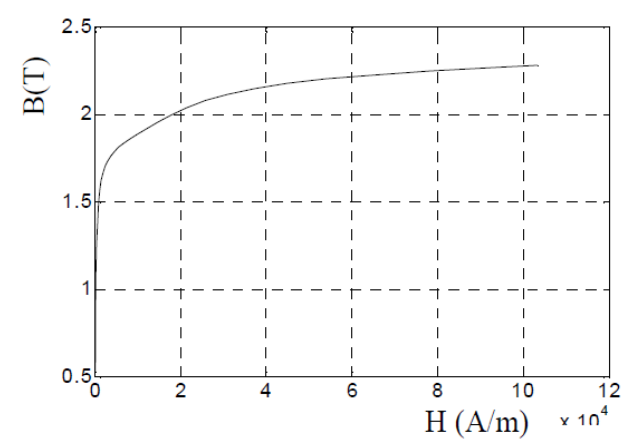

Fig. 2. Magnetization curve of the magnetic circuit

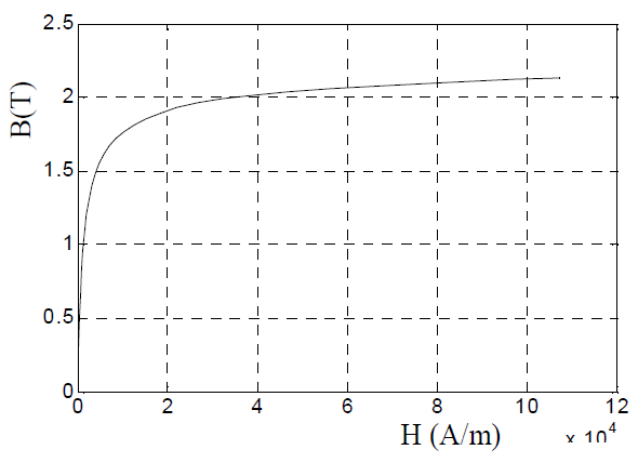

Fig. 3. Magnetization curve of the rotor

In this study, the magnetic circuit saturation is taken into account. The stator and rotor are affected by the material whose magnetization curve is shown below (Figs. 2 and 3). We must also consider the magnetization curve of the rotor influencing the distribution of the flux lines.

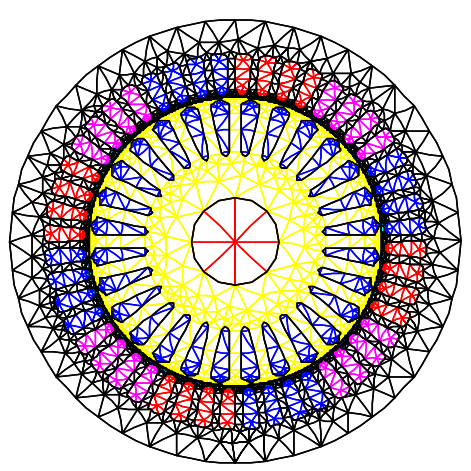

Fig. 4. Mesh of the magnetic circuit

Fig. 4 shows the mesh made on the magnetic circuit of the machine. Note that the mesh is denser in the vicinity of the air gap, where the electromagnetic exchanges between
The magnetic circuit (Fig. 1) is the induction motor whose geometry is made up of data provided by the manufacturer of the $5 \mathrm{~kW}$ induction machine. The magnetic ciris mounted on a test-bed at the laboratory AMPERE Lyon1. The use of the rotating air gap, based on the Flux2D package, allows us to consider the rotation of the rotor in the magneto-evolutionary study without making a new mesh of the machine at each position of the rotor. The distribution of the winding machine is shown in Fig. 1 ac- 
the stator and the rotor are carried out. The mesh is sparser towards the shaft and the outside of the breech to reduce the computing time without loss of information (Fig. 4). The external envelope of the machine is conductive; it is generally linked to the ground. For this reason, we applied in the simulation the Dirichlet condition on the whole contour of the machine with zero vector potential.

\section{Electrical circuit of stator}

The electrical circuit of the stator (Fig. 5) contains coils that will be linked to the magnetic scheme. They represent the conductors that will be housed in the stator slots.

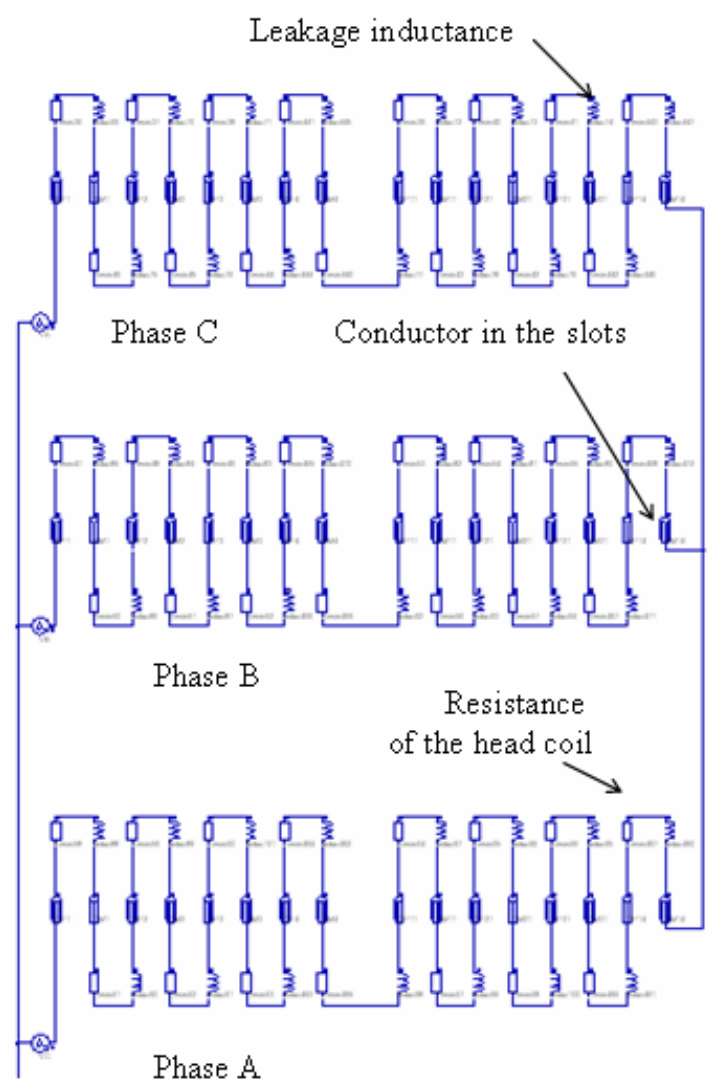

Fig. 5. Electric circuit of the stator

Between the two coils connected is a resistance representing the resistance of the head coil (3) and an inductance representing the leakage inductance slot and head coils (4) [16]-[18] .

$$
\begin{aligned}
& R_{h c}=\rho_{C o} N_{w} \frac{L_{c h}}{S_{C o}} \\
& L_{h c}=\frac{3\left(2 N_{w}\right)^{2}}{N_{s}}\left(P_{i s}+P_{c e}\right)
\end{aligned}
$$

$\rho_{C o}$ : Resistivity of copper

$N_{w}$ : Number of turns per phase
$N_{s} \quad$ : Number of stator slots

$S_{c o}:$ Sectional area of the stator winding wire

$P_{i s} \quad$ : Leakage permeance of the isthmus

$P_{c e}:$ Permeance of coil end

$L_{c h}:$ Wire length of the coil head

The calculation of leakage inductance considers the permeance of the stator slots because the surface of the notch in the magnetic circuit is completely filled with copper. The permeance of the isthmus and the slot head are considered in the magnetic representation.

The assignment of elements of the stator electrical circuits to the magnetic circuit is performed interactively using the FLUX2d software.

\section{Electrical circuit of a rotor}

The electrical circuit of a rotor (Fig. 6) contains three elements: massive conductor, resistance of the ring, and leakage inductance. Additional resistance is added to the

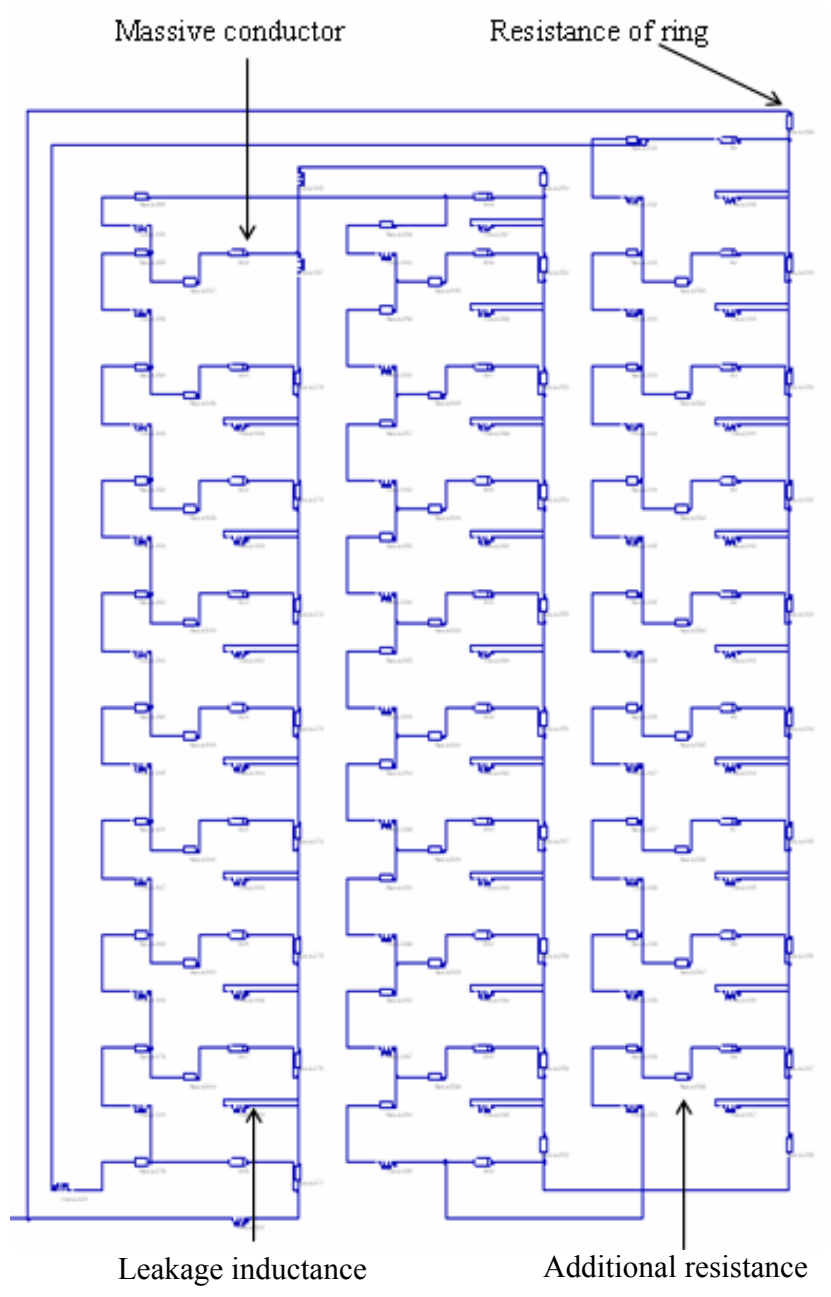

Fig. 6. Electrical circuit of the rotor 
circuit to simulate the broken bar. The calculation of leakage inductance considers the permeance of the stator slots because the surface of the slot in the magnetic circuit is completely filled with copper. The permeance of the isthmus and the head coil are considered in the magnetic representation.

For the rotor (Fig. 6), we have the following scheme.

The solid conductors represent the rotor bars and are related to the magnetic circuit. These conductors are connected by resistors. The inductors represent the resistance of the ring portions (5), leakage inductance of the rings portions, and the bar permeance (6).

$$
\begin{gathered}
R_{r i}=\rho_{a l} \frac{l_{r i}}{N_{R} S_{r i}} \\
L_{l r}=P_{i r}+\frac{P_{l r}}{2 \sin \left(\frac{p \pi}{N_{R}}\right)^{2}}
\end{gathered}
$$

$\rho_{a l}:$ Resistivity of aluminum

$P_{i r}:$ Permeance of iron

$P_{l r}:$ Permeance of the ring

The assignment of elements of the stator and the rotor's electrical circuits to the magnetic circuit is performed interactively using the FLUX2d software.

\section{Simulation}

\subsection{Healthy machine}

The components of the electrical circuit are assigned to the magnetic circuit (Fig. 7(a), (b), (c)). Magnetization of the machine to the initial state is conducted by a magnetodynamic resolution. The latter is independent of time. When the machine is magnetized, we launch the magnetoevolutionary resolution. Thus, the speed of the rotation is constantly equal to $1440 \mathrm{rpm}$, and the simulation of the stator current begins in the transitional regime (Fig. 7). Fig. 7(a) shows the distribution of equiflux lines in the magnetic circuit with the presence of symmetry in relation to the inter-polar axis. The lines of flux between the stator and the rotor are slightly deflected in the direction of the rotation of the rotor. The distribution of the induction in Fig. $7(\mathrm{a})$ is also quasi-symmetric.

Fig. 8 shows the magnetic flux density in the air gap of the machine and the spectrum of density. Fig. 9 presents the fundamental and odd harmonics. These allow the distinction between the healthy machine and the faulty machine. The author [Ben 98] showed that the fault of the broken bars creates distortion in the magnetic flux density. Thus, the harmonics specify the defects.
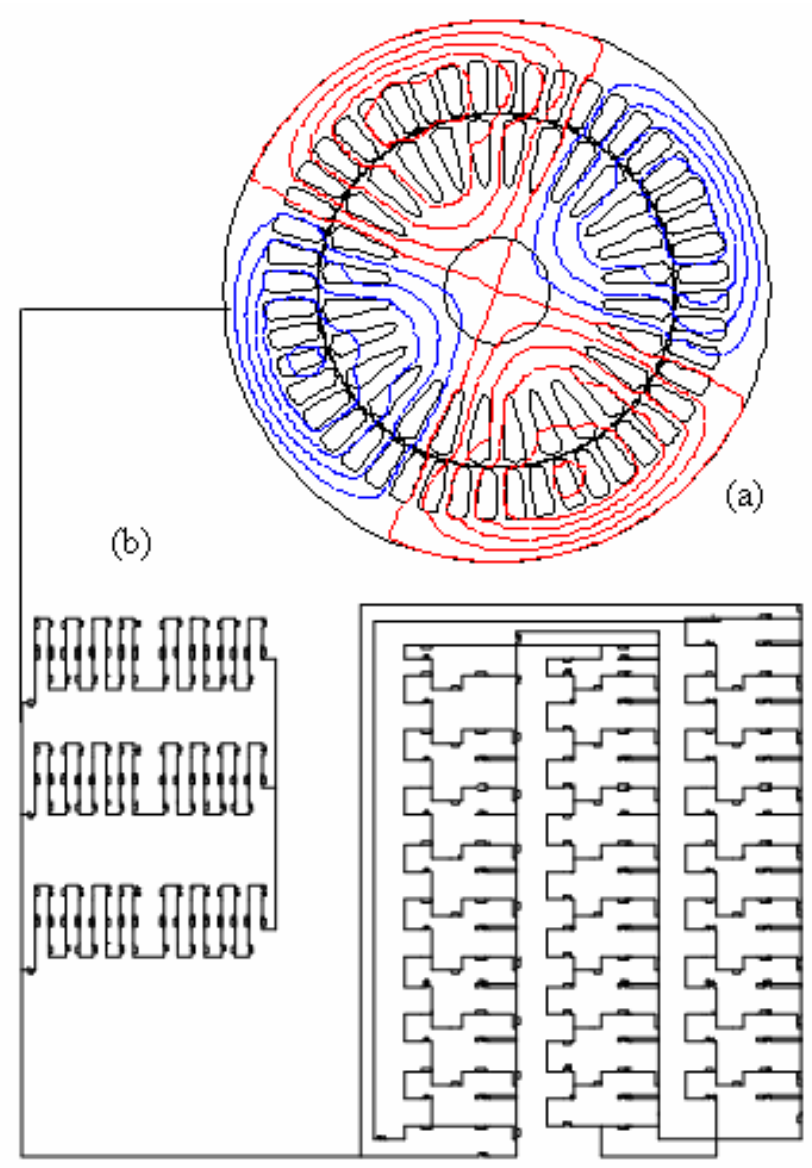

(c)

Fig. 7. Induction machine model (a) Machine geometry, (b) Stator windings, (c) Rotor model

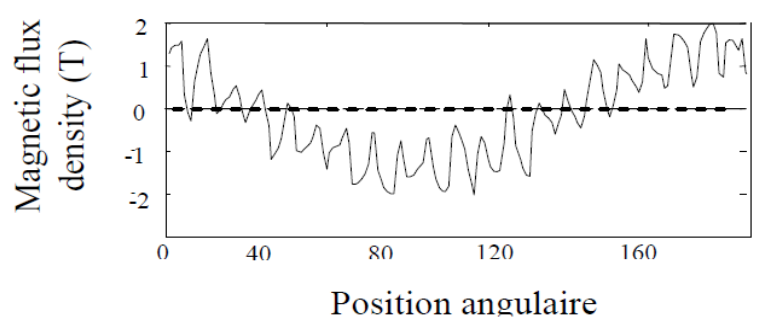

Fig. 8. Magnetic flux density in the air gap

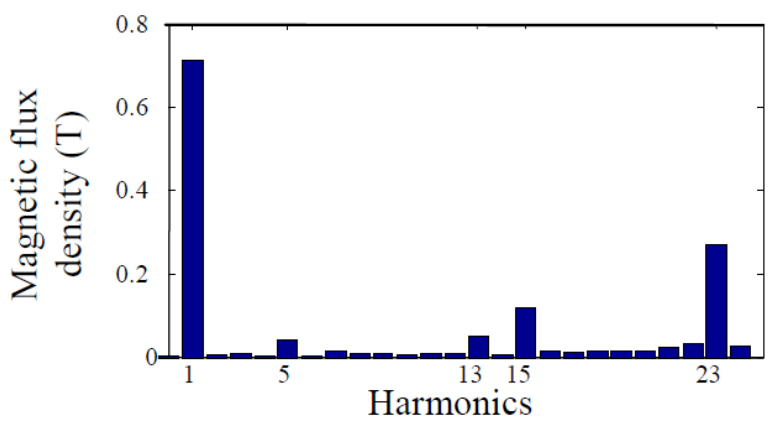

Fig. 9. Spectrum of the magnetic flux density in the air gap 


\subsection{Broken rotor bars}

To illustrate the broken bars in the rotor circuit, we assign a value of almost infinite to the resistance, which is in series with the bar, in the electrical system of the rotor. The area representing the broken bar in the magnetic circuit is filled by a non-magnetic material. As a result, the electric current no longer circulates in the broken bar but has a material effect on the distribution of field lines. The broken bars induce electromotive force (emf) in the stator windings at frequencies around the fundamental stator current. This emf generates a stator current modulation. In the current study, we intend to study the effect caused by broken bars on the stator current with no ideal supply.

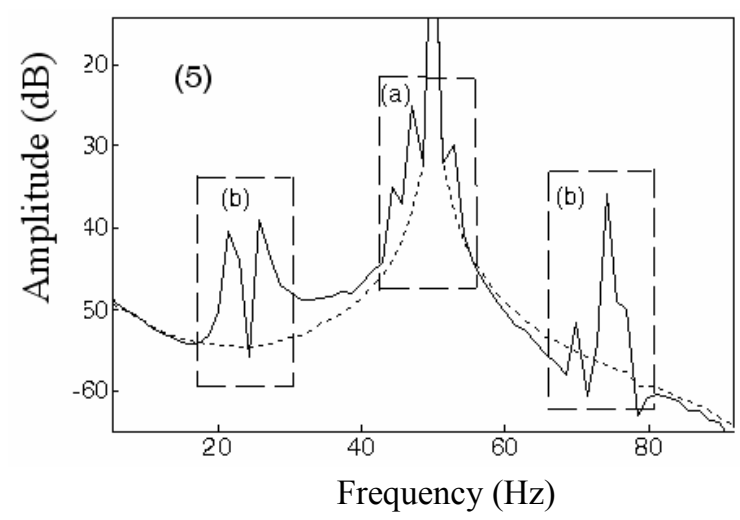

Fig. 10. Spectrum of the stator current vector of four broken bars (solid) and the healthy case (dashed)

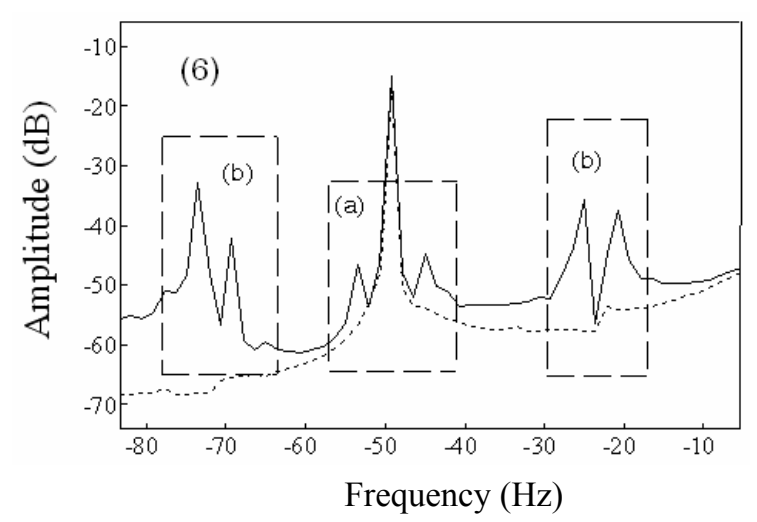

Fig. 11. Spectrum of the inverse sequence component of four broken bars(solid) and the healthy case (dashed)

The simulation model of the machine in the healthy and faulty cases is shown in Figs. 10 and 11. The model is subjected to an unbalanced voltage supply. Two broken bars induce sidebands in the spectrum of the stator current. These bands appear around the fundamental $(f)$ and its inverse symmetrical component $(-f)$. These sidebands are shown in Figs. 10 and 11. However, there are also other side bands in frames $(a, b)$ at frequencies of $\pm 22, \pm 26$
$\mathrm{Hz}$ and $\pm 70 \mathrm{~Hz}, \pm 74 \mathrm{~Hz}$. Table 1 describes and generalizes the new sidebands of the rotor faults induced in the stator windings under the condition of non-sinusoidal power from the machine.

Table 1. New sidebands

\begin{tabular}{c|c}
\hline Frequencies & Induced sidebands \\
\hline \multirow{2}{*}{$f$} & $f(k / p)-s((k / p) \pm 1), \quad k=1,3$ \\
\cline { 2 - 2 } & $f(1 \pm 2 k s)$ \\
\hline$-f$ & $-f(1 \pm 2 k s)$ \\
\hline \multirow{2}{*}{$\begin{array}{c}n=1,2 \ldots \\
n-1)\end{array}$} & $-f(6 n-1)(k / p)-s((k / p) \pm 1), \quad k=1,3$ \\
\cline { 2 - 2 }$f(6 n+1)$ & $f(6 n+1)(k / p)-s((k / p) \pm 1), \quad k=1,3$ \\
\cline { 2 - 2 } & $f((6 k+1) \pm 2 k s)$ \\
\hline
\end{tabular}

\section{Experimental Results}

The experimental bench consists of a three-phase asynchronous motor squirrel cage Leroy Somer LS 132S, IP 55, Class $\mathrm{F}, \mathrm{T}^{\circ} \mathrm{C}$ standard $=40^{\circ} \mathrm{C}$. The motor is loaded with brake powder. Its maximum torque $(100 \mathrm{Nm})$ is reached at a rated speed. This brake was designed to dissipate a maximum power of $5 \mathrm{~kW}$. Fig. 12 shows the bench motor.

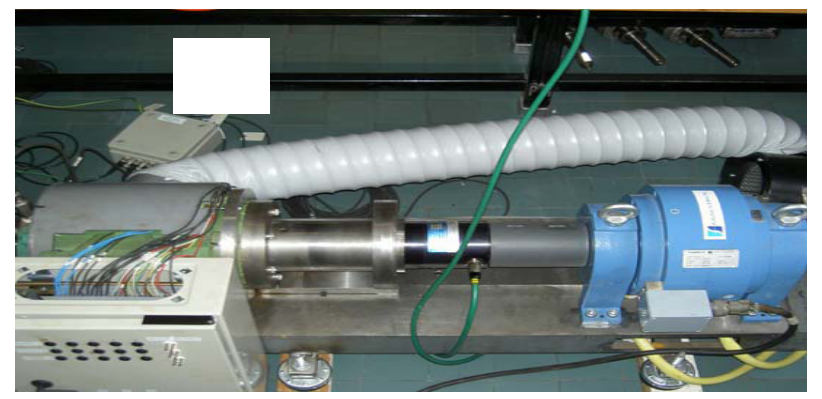

Fig. 12. Test bench of the induction motor

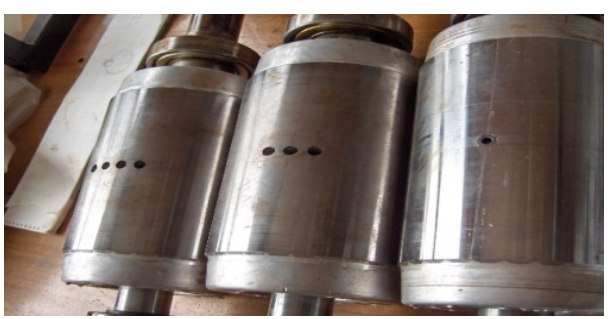

Fig. 13. Broken bars $(1,2,3)$

In the rotor fault, the bar is broken by a drilling bar of the cage squirrel (Fig. 13). Approximately 5\% of unbalanced supply is obtained with variable autotransformers placed in one phase of the network (Fig. 12). Acquisition of the current signals is carried out on a test bench; the sampling rate is $10 \mathrm{KHz}$. The number of samples per signal increases to $\mathrm{N}=10000$ samples. A test is then performed on the current signals collected at the $25 \%$ and $70 \%$ load levels. 
Fig. 14 shows the spectrum of the vector space of the stator currents. Broken bar faults induced sidebands around the following frequencies: the fundamental $50 \mathrm{~Hz}$ (Fig. 14), the negative sequence component $-50 \mathrm{~Hz}$ (Fig. 15), harmonics $-250 \mathrm{~Hz}$ (Fig. 16), and harmonics $350 \mathrm{~Hz}$ (Fig. 17). Therefore, these results are in accordance with those of the simulation.

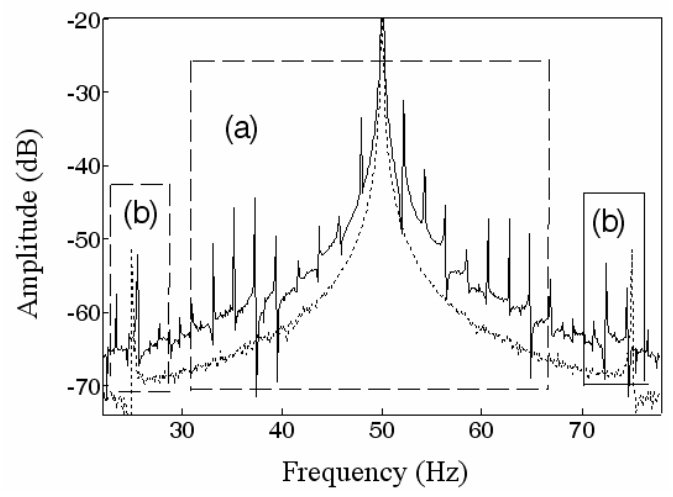

Fig. 14. Spectrum of the vector space of the stator current; three broken bars(solid) and the healthy case (dashed)

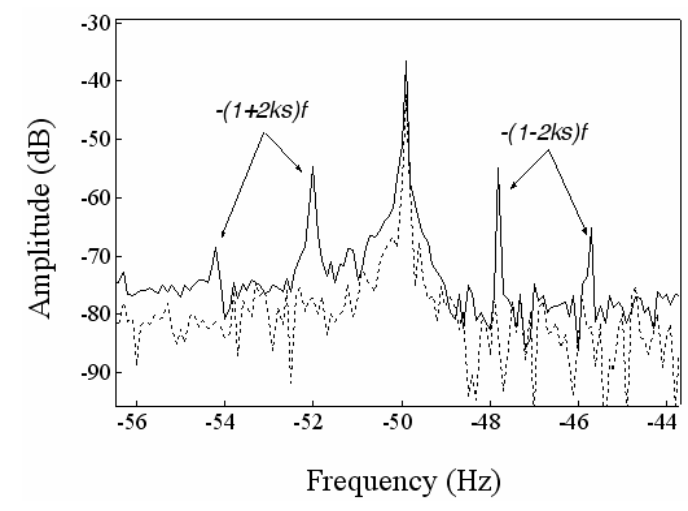

Fig. 15. Zoom image of the vector space of the stator current in the spectrum domain; three broken bars (solid) and the healthy case (dashed)

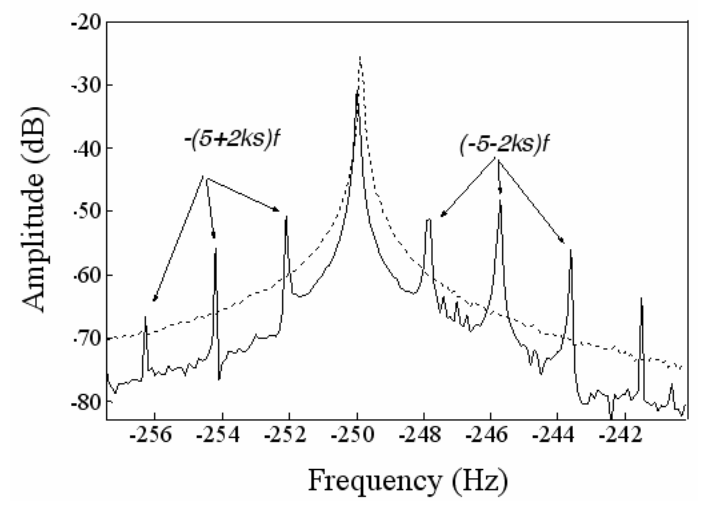

Fig. 16. Zoom image of the vector space of the stator current in the spectrum domain; three broken bars (solid) and the healthy case (dashed)

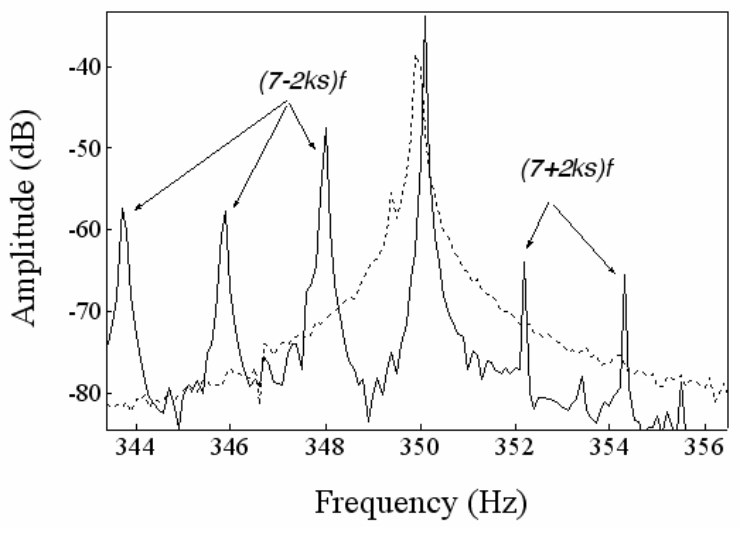

Fig. 17. Zoom image of the vector space of the stator current in the spectrum domain; three broken bars (solid) and the healthy case (dashed)

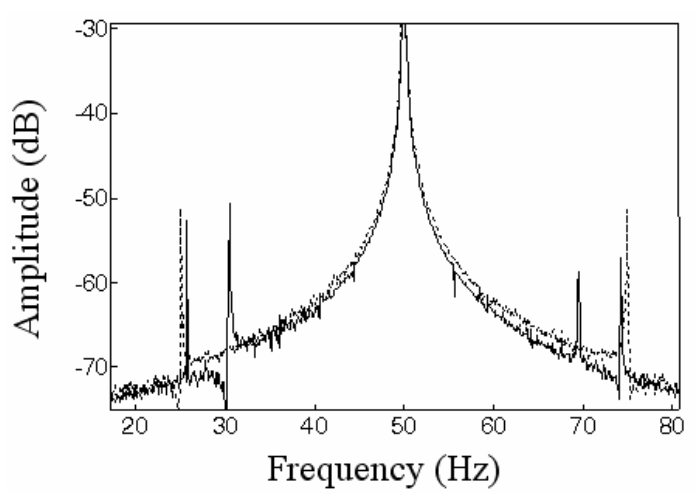

Fig. 18. Vector space of the stator current in the spectrum domain; partial broken bar(solid) and the healthy case (dashed)

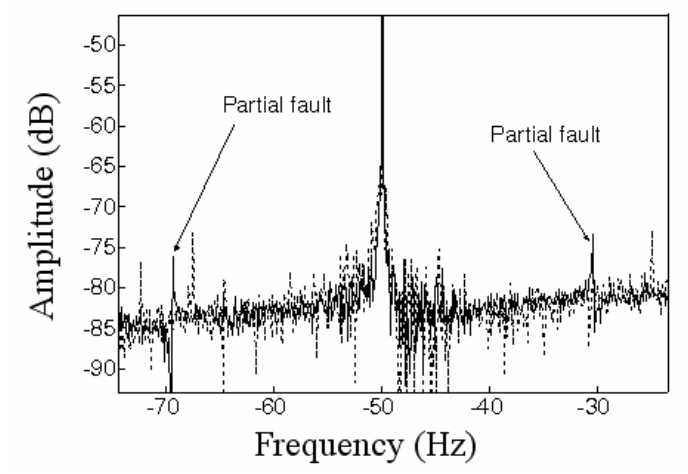

Fig. 19. Zoom image of the vector space of the stator current in the spectrum domain; three broken bars (solid) and the healthy case (dashed)

Fig. 18 shows the partial fault of a bar. Clearly, the sidebands $(1-2 \mathrm{ks}) f$ do not appear. However, other components appear at frequencies of $25 \mathrm{~Hz}, 30 \mathrm{~Hz}$ and $70 \mathrm{~Hz}, 75 \mathrm{~Hz}$. Note that the lines at $25 \mathrm{~Hz}$ and $75 \mathrm{~Hz}$ appear both in the healthy case and in the faulty case. This can be explained by the existence of a small imbalance caused by the manufacturing rotor. However, the sidebands specific to the par- 
tial fault of a bar occur as follows: $25 \mathrm{~Hz}$ and $75 \mathrm{~Hz}$ around the fundamental, $-30 \mathrm{~Hz}$ and $-70 \mathrm{~Hz}$ around the inverse sequence component $-50 \mathrm{~Hz}$ (Fig. 19), $-270 \mathrm{~Hz}$ and -230 $\mathrm{Hz}$ around the $-250 \mathrm{~Hz}$ Harmonic (Fig. 20), and $330 \mathrm{~Hz}$ and $370 \mathrm{~Hz}$ around the $350 \mathrm{~Hz}$ harmonic (Fig. 21). Therefore, these sidebands are good indicators in the early-stage diagnosis of faults due to broken bars.

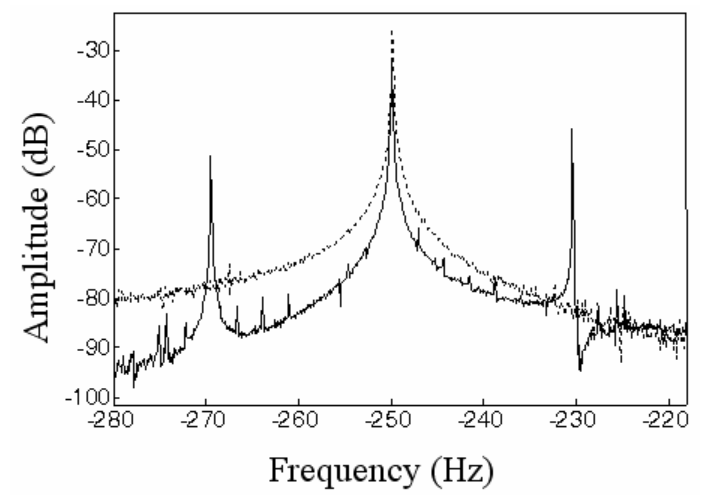

Fig. 20. Zoom image of the vector space of the stator current in the spectrum domain; three broken bars (solid) and the healthy case (dashed)

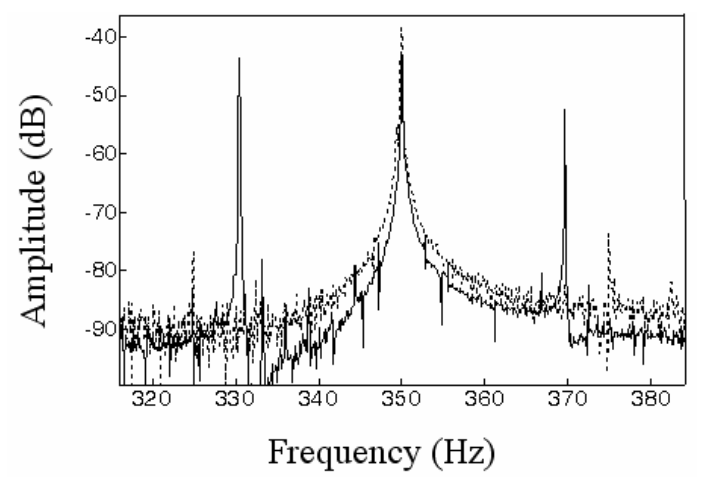

Fig. 21. Zoom image of the vector space of the stator current in the spectrum domain; three broken bars (solid) and the healthy case (dashed)

\section{Conclusion}

The simulation of the induction machine by finite element method yielded good information on the electrical behavior of the machine in both healthy and faulty cases. The simulation of the broken bars allowed the highlighting of all sidebands related to faults. Early detection is possible using the components located around the fundamental frequency $(f)$, the negative sequence component $(-f)$, and the odd frequency.

\section{References}

[1] Tsoumas, I. P. Georgoulas, G. Mitronikas, E. D. Safa- cas, A.N. "Asynchronous Machine Rotor Fault Diagnosis Technique Using Complex Wavelets" Energy conversion, ieee transactions on, Vol.23, pp.444-459, 2008

[2] Concari, C.; Franceschini, G.; Tassoni, C., "Differential Diagnosis Based on Multivariable Monitoring to Assess Induction Machine Rotor Conditions". Industrial Electronics, IEEE Transactions on, Vol..55, pp: 4156-4166, 2008.

[3] Kliman G. B., et al., "Methods of motor current signature analysis," Electric Machines \& Power Systems, vol. 20, no. 5, pp. 463-474, Sept. 1992.

[4] Kral, C.; Pirker, F.; Pascoli, G.; Kapeller, H,'.Robust Rotor Fault Detection by Means of the Vienna Monitoring Method and a Parameter Tracking Technique", Industrial Electronics, IEEE Transactions on, Vol.55, pp: 4229-4237, 2008.

[5] Mohamed El Hachemi Benbouzid," A Review of Induction Motors Signature Analysis as a Medium for Faults Detection", IEEE Trans. Ind Electronics. Vol. 47, No. 5, 2000

[6] Kliman G. B., Koegl R.A., Stein J., Endicott R.D., Madden M.W., "Noninvasive detection of broken rotor bars in operating induction motors", IEEE Trans. Energy Conv., 1988, pp 873-879.

[7] Deleroi W., "Squirrel cage motor with Broken bar in the rotor - physical phenomena and their experimental assessment”, ICEM, Budapest, 1982.

[8] Hargis C., Gaydon B.G., Kamash K., "The Detection of rotor defects in induction motors", IEE Int, Conf. on Electrical Machines. Design and Applications, pp216-220, July 1982.

[9] Filipetti F., Franceschini G., Tassoni C., Vas P., “AI techniques in induction machine diagnosis including the speed ripple effect", vol 1, IAS, , pp 655-662, 1996, California.

[10] Perovic D. K., Arkan M., Unsworth P., "Induction motor fault detection by space vector angular fluctuation", IEEE IAS, Vol 1, pp 388-394, Rome, Italy, 2000.

[11] Subhasis N., Toliyat H., "Study of three phase induction motors with incipient rotor cage faults under different supply conditions", IEEE, IAS, 1999, conference record.

[12] Ritchie E., Deng X., Jokinen T., “ Dynamic model of 3-phase squirrel cage induction motors with rotor faults ", ICEM 94, B6(2), pp.694-698.

[13] Vas P., Filippetti F., Franceschini G., Tassoni C., "Transient modelling oriented to diagnostics of induction machines with rotor asymmetries ", ICEM 94, pp.62-67.

[14] Bentounsi A., Nicolas A., "On line diagnosis of defaults on squirrel cage motors using FEM", IEEE Transactions on magnetics, vol. 34, NO,5, Sept.1998.

[15] FLUX2D, CAD package for electromagnetic and thermal analysis using finite elements FLUX2D, Ver- 
sion 7.40, Induction Machine Tutorial, 1999

[16] P. L. Alger, "The nature of induction machines", Gordon and Breach, Science pulisher inc., New York, 1965.

[17] M. Kostenko, L.Piotrovsky, "Electrical machines" MIR Publishers, Moscow 1969.

[18] G. Seguier, F. Notelet, "Electrotechnique industrielle", Technique et doc., 1977.

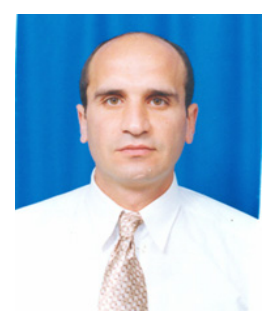

Abdesselam Lebaroud was born in Constantine, Algeria, in 1969. He received his $\mathrm{Ph} . \mathrm{D}$. degree in electrical engineering from University Claude Bernard Lyon I, Ampere Laboratory, France, in 2007. Currently, he is an Associate Professor at the Electrical Engineering Institute of Skikda University. He has conducted research on the diagnosis of electrical machines in LEG ( Laboratoire d'Electrotechnique de Constantine).

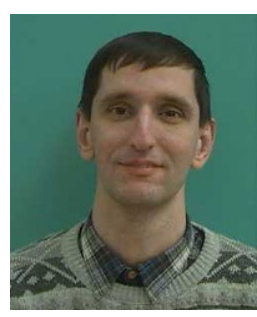

Guy Clerc was born in Libourne, France, on November 30, 1960. He received his bachelor's degree in engineering and Ph.D. in electrical engineering from the Ecole Centrale de Lyon, France, in 1984 and 1989, respectively. He is a professor in electrical engineering and teaches at the University Claude Bernard Lyon I in France. He has conducted research on the control and diagnosis of induction machines. 